\title{
Educational Reform of Aerobics Course in Sports Colleges and Universities
}

\author{
Hehua Ao \\ Institute of Physical Education, University of Yichun, Jiangxi Province, China \\ dwh0227@126.com
}

\begin{abstract}
In view of the Aerobics in sports colleges and Universities knowledge skills and practical education emphasizes only materialized, learning, and into the present situation, the concept of educating people neglect of teaching, research thinks, the value of rational Aerobics tool rationality and education. Education is unified, in order to focus the Aerobics education by '"steering' people", can achieve higher physical education culture consciousness, against the alienation of education, improve the quality of education.
\end{abstract}

Index Terms - Sports colleges and Universities, Aerobics, Education, Reform

\section{Introduction}

Aerobics as a main course of physical education colleges and universities, including many social and cultural phenomenon, at the same time, the content of education and culture connotation is rich. Over the years, the higher sports colleges and Universities Aerobics Teaching is the main technical skills to learn aerobics, in teaching how to educate the less, which makes the aerobics has the heavy technology, skills, mild educational phenomena, and then make the Aerobics Education core value deviation. Therefore, as the higher sports colleges and Universities Aerobics Course, should be the education into the concept of education and teaching, to reflect the true value of curriculum, which is the main theme of the future development of higher education, to improve the quality of higher education, the university student comprehensive healthy development to have the important meaning to promote.

\section{2. "People Oriented" Aerobics Education Reform}

A. The main problem of value rationality of Aerobics Education existence

Aerobics education value rationality refers to teachers and students personality cultivation, educational beliefs and the spirit of unremitting pursuit. Aerobics value rational education, is to ask the teachers education behavior from "what ought to be" and "what better", it mainly to the aerobics achievement tool rational education fruitful a goodness value rational guide, pay close attention to its ultimate value. At present, China's Sports College Aerobics Education or to learn the technical skills, fitness methods, emphasis on research and development of students' biology can "materialization" content, ignoring the synchronization of the project culture, personality and physical education in higher education emphasizes education combined to promote college students' core spirit of harmonious and balanced development of the individual the value rationality, implementation is not only reflected in the target, but also lies in the realization of the target mode. The modern education idea first is sustainable development, people therefore, actively explore the "integration effect of humanity" and "thing", in the higher sports colleges and Universities Aerobics in the process of education, research on the integration of "humanity" and "road", and "unity of mind and matter", namely "polymerization characters Shuangxiu".

\section{B. Aerobics education principle explanation}

Aerobics education principle is to explain the higher sports colleges and Universities Aerobics Education internal rules, the exploration of the relationship between sports aerobics and human science theory. WHO advocate a healthy person is a physiological health, mental health, social health. It follows the body, heart, group changes, improve the mechanism of education and life. The body is a structure, body function, sport ability; psychological refers to the knowledge, emotion, will, personality; social health is good interpersonal skills, ability to adapt to society. That is to say the aerobic exercises education principle is physical, heart, force ', three power in education process, "so, pay attention to the study of the biological, psychological, social three attributes, essence is the development of Aerobics Education strength, heart and external forces of the educational process.

\section{C. "People oriented" Aerobics Education Reform \\ "People-oriented" is the characteristics of Aerobics} Education essence. Learning aerobics technical skill is the main carrier of Aerobics Education, is one of the most important contents, education is the essence of education is the aerobics, aerobics is the core and soul. It is always necessary to satisfy people's all-round development, is the value of education, therefore, to establish the "people-oriented" values, to the pursuit of University "universal" and "sacred" important sign.

In the past we pay attention to explore the aerobic exercises education physical potential from a biological point of view, the effect is often not just as one wishes, this is because the aerobics soft power without heart education and external support. So the "Trinity" of Aerobics Education from the biological, psychological and social science research in three aspects: Cultivating "person" motion, it further reveals the inherent laws and external laws of Aerobics Education Development, aerobics education "important mission of fitness and life" education. 


\section{The Value Rationality of Aerobics Education Content Reform}

\section{A. "Blend of Arts and Sciences" Aerobics Education Reform}

"Prominent education, pay attention to ability, personality development" as the guiding ideology. On the basis of Aerobics education quality education reform ideas, to "integration" of the humanities and science education as one of the main ideas of Aerobics aerobics content change.

"Integration" of the humanities and science of Aerobics Education curriculum content change, is the humanity education of science education, biology, psychology, sociology, three for an inheritance, aerobics culture, training students' will, emotion and sense of responsibility education.

"Integration" of the humanities and science of Aerobics Education Thought is not only a high level of education concept, value concept is modern Aerobics Education Development, higher physical education in China towards the inevitable trend of quality education, to achieve international. "Integration" of the humanities and science of Aerobics Education Thought and its curriculum reform, is to train more rich humanistic spirit and scientific spirit education of college students, is the added value of education.

\section{B. The value rationality of Aerobics Education Practice Content Reform}

Aerobics education content reform including education and action, education and music, education and creation, education and relaxation, cultivation and evaluation etc.. In the past, Traditional Sports College Aerobics practice is the main content of teaching basic aerobics movement, combination of action and set of movements, the competitive aerobics, aerobics learning, attention is the skill teaching, research on the educational value of rational exploration less, to understand the cultural characteristics, aerobics principle and connotation is not very thorough. This makes the aerobic exercises education practice content is more onefold, superficial, there simply, light weight, value rationality deficiency phenomenon, namely the lack of cultural education. Research on value rationality aerobics education content reform, in the "people-centered" Aerobics Education Culture under the guidance of thinking, explore the aerobics education action beauty, beauty, beauty of psychological feelings, arouse the students' initiative and enthusiasm, improve the students' cognitive level of aerobics, and improve college students the body, heart, group health goal. In order to improve the aerobics sports and fitness, increased education and the industry, outstanding aerobics culture inheritance, the ability to work, training students, cultivate all-round development of sports talent, to pave the way for future employment. For example: we are learning aerobics basic movements, points to explain to students the basic actions, the pace at the foot and arm force, control and coordination, the basic requirements of the body posture, can exercise the position and effect of the muscles of the body, improve heart and lung function, improve the The new supersedes the old., enhance a constitution, at the same time to teach students aerobics basic movements, not only to the human body function has been greatly improved, but also the aerobics psychological health, personality of human development has great role in promoting. In the classroom, by grouping the creation and practice, to develop students' team spirit and cooperation consciousness, cultivate "citizen consciousness" has a very important role. Aerobics education value rationality reveals that the body, good psychological, harmonious society has important value, is a human "sports loving" rational.

Aerobics education is instrumental rationality and value rationality twin sisters, are indispensable. The tool rationality reveals that the scientific content of aerobics, aerobics content namely, principles and methods, value rationality is through the inheritance of aerobics and cultural connotation, promoting education level, improve students' soul reason, is the high level of education. Practice has proved, the tool rationality and the value rationality of Aerobics Education is the inevitable trend of quality education. To the "peoplecentered" aerobics education reform, is to realize the education of "instrumental rationality" and "value" of harmony and unity, is to cultivate "superego" - the sacred national and universal unified world citizens, to improve Aerobics Education culture charm and tension quite value.

Aerobics Education into the education idea in each link. In the aerobics education process is not only the cultivation of knowledge and ability, more important is a professional quality education. In the past, the traditional aerobics teaching skills, light weight technology oriented teaching is "light weight" education. In the teaching of Aerobics education advocated to "teach" technical education, its essence is taught by the rich "human nature" of the aerobics knowledge skills, which taught aerobics knowledge and skills as an educational "carrier", cultivate the humanistic spirit and scientific spirit of the aerobics talents.

\section{Conclusions}

First of all, to "the higher sports colleges and universities education oriented" aerobics education reform, is the main content of Aerobics Education to improve the level of physical education colleges and universities.

Secondly, the higher Sports College Aerobics Education personnel training mode of reform, this is the core of the higher sports colleges and Universities Aerobics healthy development of education in.

Finally, the tool rationality and the value rationality of unity of Aerobics Education Reform, this is the inevitable trend of realizing quality education.

\section{References}

[1] Xiaojun. Zhang, "The loss and reconstruction of competitive education in China," Journal of Physical Education, vol. 12, no. 12, pp. 32-35, December 2009.

[2] Qiliang. Hu, Zili. Lan, Yunling. Wang, "A Strategic Study of the Interaction between campus P.E. culture in Colleges and Universities and the Ideological and Political Education for Undergraduates," Journal of Capital Institute of Physical Education, vol. 22, no. 2, pp. 70-73, March 2010.

[3] Jisheng. Xue, Hongyan. Wang, "A Theoretical and Practical Study on Harmonious Education of Integration of Humanism and Science in Advanced Sports Institutions," Journal of Beijing Sport University, vol. 31 no. 5, pp. 654-656, May 2008.

[4] Hong. Zhao, Aerobics education, $3^{\text {rd }}$ ed., Changchun: The Jilin People's Republishing House Press, 2006, pp.1-90 